\title{
Artificial intelligence technologies as a factor in increasing the economic efficiency of generating companies
}

\author{
Elena Troianova ${ }^{1,2}$, Evgenia Lerman $^{3}$,Elena Baliasnikova $^{4}$, Ina $_{\text {Fiutik }}^{5}$, and Ekaterina Savelieva $^{5}$ \\ ${ }^{1}$ Novosibirsk State Technical University, Novosibirsk, Russia \\ ${ }^{2}$ Novosibirsk State Pedagogical University, Novosibirsk, Russia \\ ${ }^{3}$ Siberian Transport University, Novosibirsk, Russian Federation, Novosibirsk, Russia \\ ${ }^{4}$ Western Branch of the Russian Academy of National Economy and Public Administration under the President of the Russian \\ Federation, Kaliningrad, Russia \\ ${ }^{5}$ Siberian State University of Water Transport, Novosibirsk, Russia
}

\begin{abstract}
The article deals with the application of modern artificial intelligence technologies that affect the economic efficiency of generating companies. Scientific novelty lies in the approach to the consideration of artificial intelligence as both external and internal factors of influence on the dynamics of production and consumption of electricity. As a result of the study, the key aspects of the growth of the economic efficiency of the activities of energy generating companies are highlighted and characterized. The forecast of the prospective sustainable development of certain areas of the energy sector and the increase in energy consumption is presented.
\end{abstract}

\section{Introduction}

The large-scale spread of coronavirus infection since March 2020 and the forced government restrictive measures have had a significant negative impact on the Russian economy.

Energy, being the basic branch of the domestic economy, provides electric and thermal energy for the needs of the industrial sector, the agro-industrial complex and the population of the country. A unified energy system (UES) has been created in Russia, which includes $90 \%$ of generating companies, 69 energy systems in 79 constituent entities of the Russian Federation. These enterprises operate as part of six interconnected power systems (IES) operating in parallel - IES of Center, South, North-West, Middle Volga, Urals and Siberia and IES of the East, operating in isolation from the UES of Russia. In addition, the UES of Russia carries out parallel work with the IES of Ukraine, IES of Kazakhstan, IES of Belarus, the energy systems of Estonia, Latvia, Lithuania, Georgia and Azerbaijan, as well as with NORDEL (communication with Finland through the DC link in Vyborg).

The huge potential for electricity generation is also evidenced by the fact that the basis of the Russian energy system is made up of about 600 power plants with a total capacity of $210 \mathrm{GW}$. Thermal power plants account for two thirds of generating capacity. About $55 \%$ of the capacity of thermal power plants are combined heat and power plants (CHP), and $45 \%$ are condensing power plants (CES). The capacity of hydraulic (HPP), including pumped storage (PSPP) power plants is $21 \%$ of the installed capacity of power plants in Russia. The capacity of nuclear power plants is $17.2 \%$ of the installed capacity of the country's power plants.

Quarantine restrictions caused by the coronavirus pandemic in 2020 slowed down economic activity in all sectors of the domestic economy. This significantly affected the level of electricity consumption. According to the Ministry of Energy, energy consumption in Russia has decreased by $4 \%$ on average. In some regions, for example, in the Volga region, the decline reached 10\%, in the energy system of Moscow and the Moscow region $-7 \%$.

The analysis of the dynamics of energy consumption by industry showed that the greatest decrease occurred in mechanical engineering - by $14.5 \%$, in railway transport - by $6.5 \%$ and in metallurgy - by $3.4 \%$.

A decrease in demand for electricity in the Baltic and Scandinavian countries in the first half of 2020 led to a decrease in the volume of electricity exports. As a result, by the end of 2020, the volume of electricity generation in Russia will decrease by 3\% compared to the same indicator in 2019, which significantly affected the decrease in the efficiency of the energy sector.

\section{Materials and methods}

The changed external environment creates the need to use, when assessing the economic efficiency of the energy generating companies, not only their internal data, but also data obtained through market research. In modern economic conditions, it is necessary that performance indicators take into account all relevant parameters of the external environment, including 
market conditions, changes in macroeconomic indicators, as well as the influence of government regulation on certain market factors.

The energy strategy developed by the government of the Russian Federation defines the goals and objectives of the long-term development of the country's energy sector for the coming period; priorities and benchmarks, as well as mechanisms of state energy policy at certain stages of its implementation, ensuring the achievement of the set goals.

In the current period, the Decree of the Government of the Russian Federation of 09.06.2020 N 1523-r "On approval of the Energy Strategy of the Russian Federation for the period up to 2035" indicates the main goal of further development of the energy sector of the Russian Federation for the period up to 2035. This document, on the one hand, outlined the direction for maximum assistance to the socio-economic development of the country, and on the other hand, is aimed at strengthening and maintaining the position of the Russian Federation in the global energy sector, at least for the period until 2035.

Achieving this goal will require an accelerated transition or, as stated in the document, a "modernization breakthrough" to more efficient, flexible and sustainable energy, capable of adequately responding to the challenges and threats in its area and overcoming existing problems. One of the characteristics of the transition to highly efficient energy production is the digital transformation and intellectualization of the sectors of the fuel and energy complex, as a result of which all processes in the energy sector will acquire a new quality, consumers of products and services of the sectors of the fuel and energy complex will receive new rights and opportunities.

The main challenge for the domestic energy sector is improving energy efficiency. The dynamics of demand for electricity is a fundamental factor affecting the efficiency of generating companies. This is primarily due to the coincidence in time of the process of production and consumption of electricity and uneven load, which is one of the features of energy production. A more even schedule of consumption allows using the power of the power plant with the highest utilization factor, which helps to reduce production costs and, accordingly, cost.

A modern approach to solving this problem is the use of artificial intelligence technology in the fundamental production processes of generating companies. Analysis of the information available in open access shows that the main areas of application of artificial intelligence in the energy sector can currently be combined into three main groups.

The first group includes methods for predicting the main components of energy processes. In this group, the use of artificial intelligence technologies is aimed at making a forecast of key production indicators: energy production and consumption, optimization of equipment operation.

The second group includes directly methods of increasing energy efficiency. One of the tools for this area of using artificial intelligence technologies is monitoring data on actual energy consumption. As already noted, one of the main technological features of the energy sector is the simultaneity of the process of production and consumption of energy, caused by the impossibility of its accumulation, as well as the high speed of transportation from the producer to the consumer. As a result of this technology in the electric power industry, the production mode is determined by the consumption mode.

The unevenness of the daily consumption of electricity in Russia is influenced by a number of factors. This is a significant territory of the country, various natural, economic and social conditions, population density, distribution of productive forces, etc. Within one territory, there is a decline in consumption at night, the daytime peak falls on 10 12:00, evening - 17-20 hours.

In addition, each consumer has his own load schedule, which is associated with the peculiarities of the type and scale of activity, the mode of operation, the structure of labor resources and other features of functioning. With regular irregularities in electricity consumption, the demand for it must be covered in accordance with the established load schedule of the power plant. It should be noted that in a certain period of time, the consumer is provided not only with the required amount of electricity, but also with the amount of reserved power. This capacity is necessary to quickly cover the additional needs of consumers, as well as to maintain the efficiency of the energy system.

Ultimately, uneven consumption significantly affects the dynamics of growth in prices and tariffs for electricity. This is associated with additional costs for:

- maintenance of additional generating capacity, capacity of networks and transformer substations,increasing and decreasing the load several times during the day, which accordingly increases the specific fuel costs and reduces the service life;

- reducing the risk of emergency shutdowns, failure to prevent which leads to a decrease in the quality of electricity, an increase in losses in the lines;

- load charts are the most important tool for technological planning and production management, a factor in increasing the reliability of power supply and its economic efficiency.

The third group of application of artificial intelligence in the energy sector is aimed at intellectualizing the results of monitoring and assessing the state of energy facilities, as well as load management algorithms in generating companies. This is primarily due to the fact that energy is one of the most capitalintensive industries. The main share of investments is directed to maintaining the technical condition of power equipment and ensuring reliable power supply to consumers. This is facilitated by the introduction of digital solutions and the modernization of control platforms through the widespread use of artificial intelligence technology.

Artificial intelligence technologies help reduce repair costs, eliminate the consequences of technological disruptions, and reduce labor costs and investments in equipment upgrades. Predictive analytics solutions can 
reduce the cost of repairing power equipment in half and reduce downtime by $40 \%$.

The forecast compiled by the Russian Ministry of Energy assumes that the introduction of artificial intelligence technologies in the electric power industry by 2025 will provide an economic effect of more than 530 billion rubles, of which about 180 billion rubles can be saved by eliminating potential electricity losses.

To achieve such indicators within 5 years, it is necessary to increase the volume of investments in the market of artificial intelligence technologies from 3-7\% of the IT budget, which are invested by Russian energy companies up to $10-20 \%$.

Another modern and very promising direction for increasing electricity consumption is the development of the electric vehicle market. According to the agency "Autostat", in the first half of 2020, the Russian market for electric vehicles increased by $45.7 \%$ compared to the same period in 2019. It should be noted that in absolute terms, as of July 1, 2020, this is only 7925 passenger cars, which is $0.02 \%$ of the country's automotive market 8-9 billion kWh.

Nowadays, the infrastructure for electric vehicles is rapidly developing. Today, more than a million charging stations operate worldwide. According to Bloomberg New Energy Finance, the number of petrol stations has doubled in three years. According to Bloomberg forecasts, in 2025 one of ten new cars will be fully electric and, accordingly, by 2040 the number of charging stations in the world will increase to 12 million units.

One of the factors influencing the development dynamics of the charging station network is the use of artificial intelligence technologies. The charging process for electric vehicles must be coordinated, while electricity storage and network stabilization must be carried out. The solution to this problem is possible by regulating the demand for energy consumption for charging an electric vehicle in accordance with price signals and accessibility to energy. The use of artificial intelligence in the analysis and coordination of these actions will help to avoid disruptions in the process of supplying electricity and its storage, which in turn will increase energy efficiency in general.

In Russia, compared to the world's leading markets, the demand for electric vehicles remains relatively low, which is primarily due to the lack of government support. For the development of this segment of the country's automotive market, it is necessary to abolish import duties on electric vehicles, provide subsidies for individuals and the possibility of refunding income tax when purchasing an electric car.

Another factor negatively affecting the development of the electric vehicle market is the underdeveloped infrastructure. Potential owners of electric vehicles are intimidated by the likelihood of not finding a charging station near a parking lot or during a long trip. To accelerate the development of this area, government support is also needed, which should consist in the development of infrastructure and simplification of the procedure for installing charging stations by individuals.
It should be noted that the charging station network currently tends to develop steadily. An example is the Novosibirsk region. Currently, more than 500 electric vehicles are registered in the region, 28 electric car charging stations have been installed, 25 of them are located in Novosibirsk, including eight direct current (fast) stations with a capacity of $24 \mathrm{~kW} / \mathrm{h}$ and 17 alternating current stations with a capacity of $22 \mathrm{~kW} / \mathrm{h}$. Three stations are installed on the P-255 highway "Novosibirsk-Tomsk-Kemerovo." By the end of 2021, an additional 7 stations will be created on the main transport routes of the region. Each station with a capacity of $22-24 \mathrm{~kW}$ is capable of charging two cars simultaneously. Considering that, on average, one car is charged at the station for 35 minutes, the maximum capacity of the station is 40 cars per day.

\section{Literature Review}

The problem of using artificial intelligence has recently occupied a special place in scientific publications of many foreign authors. First of all, the authors note that the use of artificial intelligence significantly changes the organization's management system. The development of the technological process is accelerating, which forces the management to change approaches to the formation and management of innovations. The problem of replacing labor resources with artificial intelligence technologies and transforming innovations into a digital organization does not remain unattended either.

The introduction of artificial intelligence in today's intelligent society requires automated planning and data analysis using intelligent applications, infrastructure, systems and networks. The process of solving this problem is characterized by a large gap between learning processes and operational processes of activity. As a result, two main problems arise: the first is the requirement to develop a special method for the formation and management of huge amounts of data. The second challenge is optimizing human-machine interaction with appropriate intelligent service and training. A number of authors propose a solution to these problems through the development of a new method aimed at closing the above gap using extended diagnostics (AD).

At present, a large number of articles by both foreign and Russian authors are devoted to the problem of using artificial intelligence technologies in the energy sector. However, it should be noted that Western authors devoted their publications to this problem much earlier. So, in 2006 Soteris A. Kalogirou published the book "Artificial intelligence in energy and renewable energy systems." In it, he presented applications for the application of artificial intelligence in the design and simulation of energy systems and renewable energy sources: solar, wind, biomass and hydrogen. In all these areas, the application of artificial intelligence technologies is considered. Such technologies are based on artificial neural networks, genetic algorithms, fuzzy logic and their combination, which the author calls hybrid systems. It should be noted that the proposed 
methods are widely used in artificial intelligence technologies currently used in the energy sector.

The problem of applying conventional methods of data analysis in modern economic conditions does not satisfy the production needs of generating companies. Several artificial intelligence projects in the energy sector are trying to solve this problem. At the same time, the problem of the lack of unified interface specifications between the proposed systems arose. Authors Peng Liu, Wei Jiang, Hongjian Sun in their article describe an artificial intelligence platform for force fields. The proposed system uses deep learning technology to support natural language processing and computer vision services. The proposed system includes: algorithm, model and service support for powerful corporate applications. The system also provides a large number of heterogeneous data processing, libraries of algorithms, intelligent services for managing models of a typical application and other services for different levels of business processes of an energy company.

Kumba Sennaar, AI Analyst at Emerj, examines examples of AI technologies in renewable energy companies. The use of artificial intelligence is considered in terms of three main areas: energy forecasting, energy efficiency and energy availability.

The main direction of application of artificial intelligence remains the adoption of more effective solutions to reduce energy losses and promote environmentally sound and energy consumption.

A number of authors: Ioannis Antonopoulos, Valentin Robu, Steve Wattam consider the use of artificial intelligence and machine learning technologies to solve various problems as one of the methods for solving the problem of rational energy consumption. These tasks include: studying consumers, their attributes and preferences, issues of dynamic pricing, planning and management of devices, teaching how to stimulate the reduction of time to eliminate accidents and and form a system of material incentives for trouble-free operation in power grids.

Russian authors, Dmitriy Raspopov and Pavel Belousov, proposed a solution to the problem of rational power consumption through the use of a Smart Socket Smart Energy device for public and industrial power grids. An algorithm was developed for determining the type of electricity consumer in the general power supply network using the X G Boost machine learning model - a system of solutions with an extreme gradient. The problem of rational energy consumption in industrial production and the use of energy-saving technologies in the most energy-intensive industries in order to increase the competitiveness of manufactured products is considered in the article by the authors Rüdiger Rentsch, Carsten Heinzel, E. Brinksmeier. The solution to this problem, according to the authors, is laid in the optimal design of the production chain and technological process using methods artificial intelligence. The genetic algorithm, combined with the suitability function, was used to find the design of the production chain and the set of process parameters with the lowest energy and resource consumption for efficient production of products.
The conducted review of foreign publications allows us to conclude that the main areas of application of artificial intelligence technologies in the energy sector are the organization of the production process and rational energy consumption, the development of consumption of renewable energy sources and the formation of a system for storing electricity and stabilizing the network.

This is due to the constant problem of unreliability of renewable energy sources, such as wind and solar energy, since they depend on weather conditions and, accordingly, often change their power. Another relevant area of application of artificial intelligence technologies is the development of the infrastructure of the electric vehicle market. In today's economic conditions, a number of the world's leading car manufacturers are restructuring their production in order to develop electrical technologies, which, one way or another, will entail the development of the corresponding infrastructure and the automotive market as a whole.

\section{Results}

As a result of studying the problem of using modern technologies of artificial intelligence, the key aspects of the growth of the economic efficiency of the activities of energy generating companies have been identified and characterized. One of the main aspects is the use of artificial intelligence to improve the efficiency of production and consumption of electricity. The use of AI is aimed at three main components of managing the activities of generating companies: forecasting the main parameters of energy processes, assessing the state of energy facilities, monitoring data on actual energy consumption and intellectualizing the processing of its results. The application of this approach allows us to consider it as an internal factor influencing the economic efficiency of the activities of energy generating companies.

A modern and very promising direction for increasing electricity consumption is the development of the electric vehicle market. An increase in the share of electric vehicles in the structure of the Russian car park from $0.02 \%$ at present to $4-5 \%$ will serve as an impetus for the development of infrastructure for them, which, in turn, will contribute to an increase in annual electricity consumption by $8-9$ billion / $\mathrm{kWh}$..

The use of artificial intelligence technologies in servicing the infrastructure of electric vehicles acts as a factor contributing to increased energy efficiency by reducing disruptions in the process of supplying and storing electricity and increasing the performance of energy generating companies.

\section{Conclusion}

In conclusion, it should be noted that within the framework of the Energy Strategy of the Russian Federation for the period up to 2035, the main task of the electric power industry within the framework of spatial and regional development is to increase the efficiency of 
the power grid complex. The complex of key measures that ensure the solution of the problem includes such measures as the transition to risk-oriented management of production assets in the power grid complex based on digital technologies, the creation of intelligent systems for electricity metering. ${ }^{\mathrm{c}}$

These measures are directly related to the use of artificial intelligence technologies. It is safe to say that the further development of technologies will make it possible to qualitatively predict the demand for energy resources, assess the reliability of technical equipment, thereby helping to minimize the risks of unreasonable costs and losses and significantly increase the growth of economic efficiency of generating companies.

\section{References}

1. A. Metelnikov, Russian energy in 2020: challenges and realities [Electronic resource], Energy News (2020) Available at: https://novostienergetiki.ru/rossijskayaenergetika-v-2020-m-godu-vyzovy-i-realii/

2. Ministry of Energy of the Russian Federation [Electronic resource] Available at: https://minenergo.gov.ru/activity/statistic

3. Energy strategy of Russia for the period up to 2035 [Electronic resource] Available at: https://ac.gov.ru/files/content/1578/11-02-14energostrategy-2035-pdf.pdf

4. On approval of the Energy Strategy of the Russian Federation for the period up to 2035, Order of the Government of the Russian Federation, 1523-r (9 July 2020) Available at: http://www.consultant.ru/document/cons_doc_LA W_354840/d6f20f5fdbee2bf9d4e11 e67b77a307fe e59f158

5. A. Mogilenko, Application of artificial intelligence algorithms in the world energy [Electronic resource], Newspaper "Energy and Industry of Russia", 13-14, 345-346 (July 2018) Available at: https://www.eprussia.ru/epr/345346/4513899.htm

6. Experts: Russian energy specialists will save trillions of rubles due to artificial intelligence [Electronic resource], TASS (23 December 2020) Available at: https://tass.ru/ekonomika/10330409

7. V. Loboda, The Russian market of new electric vehicles doubled in 2020 [Electronic resource], Analytical agency "Autostat" (28 January 2021) Available at: https:/yandex.ru/turbo/autostat.ru/s/news/47137/

8. E. Dubinkin, Electric vehicles: If there is infrastructure, there will be demand [Electronic resource] Available at: https://www.m.eprussia.ru/epr/400/3262168.htm

9. N. Haefner, J. Wincent, O. Gassmann, Artificial intelligence and innovation management: A review, framework, and research agenda [Electronic resource], Technological Forecasting and Social Change, 162, 120392 (18 October 2020) Available at: https://reader.elsevier.com/reader/sd/pii/S004016 252031218X?token=221F4EA74E45B0253CAF FFCA18B54CFC5DD956E8B0DFB2822D86F45 8948CDA6943F8914C487D6C90FF1ED8D8660 4090B

10. R. Foresti, S. Rossi, N. Delmonte, Smart Society and Artificial Intelligence: Big Data Scheduling and the Global Standard Method Applied to Smart Maintenance [Electronic resource], Engineering, 6 (7), 835-846 (29 January 2020) Available at: https://reader.elsevier.com/reader/sd/pii/S209580 9920300266?token=1BCECADEF6A6AF1BBA3 EC6ABD83A4B2A60EB1343A5013F9FB6A605 924E5B8CEDCC29C5EC7D86680C25731EF396 $21 \mathrm{~F} 488$

11. A. Soteris, Kalogirou Artificial intelligence in energy and renewable energy systems [Electronic resource] Available at: https://www.researchgate.net/publication/411171 70_Artificial_intelligence_in_energy_and_renew able_energy_systems

12. P. Liu, W. Jiang, H. Sun, Research and application of artificial intelligence service platform for the power field, Global Energy Interconnection, 3 (2), 175-185 (April 2020) Available at: https://reader.elsevier.com/reader/sd/pii/S209651 1720300517?token=D3D05B175DB592A729569 8EB0BA6CD9C7CA534ADA04F5647AC88A05 8BE0BECC6EEFE6E393053FA41A1550C92612 582E2

13. K. Sennaar Artificial Intelligence for Energy Efficiency and Renewable Energy - 6 Current Applications [Electronic resource] Available at: https://emerj.com/ai-sector-overviews/artificialintelligence-for-energy-efficiency-and-renewableenergy/

14. Y. Himeur, K. Ghanem, Abbes Amira Artificial intelligence based anomaly detection of energy consumption in buildings: A review, current trends and new perspectives [Electronic resource], Applied Energy, 287, 116601 (9 February 2021) Available at: https://reader.elsevier.com/reader/sd/pii/S030626 1921001409? token=CE0F2891D972D47E04CFD 683E9D918D40C6E91C82FF78ED83E2EC1975 96BF1BD5C69DD82A25702C1B4902D920BAF E8D1

15. I. Antonopoulos, V. Robu, S. Wattam, Artificial intelligence and machine learning approaches to energy demand-side response: A systematic review [Electronic resource], Renewable and Sustainable Energy Reviews, 130, 109899 (10 June 2020) Available at: https://reader.elsevier.com/reader/sd/pii/S136403 212030191X?token=44EA325F499599A24A009 A830947103181C12E098339AA976A46BC2E3 


\section{C1081B29D0AE4B5CE0F2FCACDAB78D3617 1C5D4}

16. D. Raspopov, P. Belousov, Development of methods and algorithms for identification of a type of electric energy consumers using artificial intelligence and machine learning models for Smart Grid Systems [Electronic resource], Procedia Computer Science, 169, 597-605 (15 April 2020) Available at: https://reader.elsevier.com/reader/sd/pii/S187705 0920303276? token $=96555 \mathrm{DF} 4 \mathrm{D} 4502528 \mathrm{D} 4 \mathrm{~A} 6 \mathrm{~F}$ BF514D84A5E1382E4A1A46BE3DEF95C9714 7AF076F429F680FCA0F25CAEB3D76230C6B2 15DA

17. R. Rentsch, C. Heinzel, E. Brinksmeier, Artificial Intelligence for an Energy and Resource Efficient Manufacturing Chain Design and Operation [Electronic resource], Procedia CIRP, 33, 139144 (2015) Available at: https://reader.elsevier.com/reader/sd/pii/S221282 7115006691?token=0054E23241 AE22CF4EEA3 960363327D62324CA35EF906A99D36EBDA22 B0DB07BB50212DAA62D1054DB4A490CC80 AA135. 